\title{
Temporal variability in lotic macroinvertebrate communities associated with invasive signal crayfish (Pacifastacus leniusculus) activity levels and substrate character
}

\author{
Kate L. Mathers $\mathbb{D}^{\cdot}$ Stephen P. Rice Paul J. Wood
}

Received: 25 February 2017/ Accepted: 2 September 2017/Published online: 7 September 2017

(C) The Author(s) 2017. This article is an open access publication

\begin{abstract}
Invasive signal crayfish (Pacifastacus leniusculus) are considered to be the most prevalent non-native crayfish species in Europe. Where large populations become established they have significant and long-term effects on benthic macroinvertebrate communities. However, much less is known about how community effects associated with crayfish invasion change in the short-term as a function of varying activity levels during the summer months. We examined the macroinvertebrate community composition of two lowland UK rivers, one which supported a well-established non-native crayfish population (invaded) and one in which crayfish had not been recorded (control). Colonisation cylinders were deployed which recorded community composition over a 126-day time period. Results indicate that once the activity period commences, invasive crayfish consistently altered macroinvertebrate community structure regardless of substrate character. Invaded communities displayed reduced beta-diversity compared to control sites. However, effects on the macroinvertebrate assemblage varied over the period
\end{abstract}

Electronic supplementary material The online version of this article (doi:10.1007/s10530-017-1557-3) contains supplementary material, which is available to authorized users.

K. L. Mathers $(\varangle) \cdot$ S. P. Rice · P. J. Wood

Department of Geography, Centre for Hydrological and

Ecosystem Science, Loughborough University,

Loughborough, Leicestershire LE11 3TU, UK

e-mail: k.mathers@lboro.ac.uk when crayfish were active probably reflecting the behavioural activity of crayfish (which intensifies with increasing water temperature and during the spawning season) and life histories of other macroinvertebrates. The results indicate that crayfish invasions modify macroinvertebrate community composition, but over shorter timescales, the effects vary associated with their activity levels.

Keywords Colonisation $\cdot$ Non-native $\cdot$ Life-history traits $\cdot$ Habitat template $\cdot$ Fine sedimentation

\section{Introduction}

Across the globe invasive species are spreading rapidly and represent one of the most significant threats to biodiversity, economic development and human health (Simberloff et al. 2013; Early et al. 2016). Invasive crayfish species are considered to be some of the most extensively distributed aquatic invasive species worldwide and within Europe the signal crayfish (Pacifastacus leniusculus; Dana) is one of the most widespread and successful non-native crayfish species (Hudina et al. 2015). Crayfish are widely acknowledged to be keystone species and often dominate benthic biomass where they occur (Crandall and Buhay 2008). Their polytrophic feeding habits ensure that if they reach high population densities 
within invaded ecosystems, their effects are extensive and often resonate throughout the food web (Momot et al. 1978; Guan and Wiles 1998).

Despite an increasing number of studies investigating the ecological effects of invasive crayfish, much of the research has been conducted in lentic ecosystems (e.g. Nyström et al. 2001; Ercoli et al. 2015a, b, Ruokonen et al. 2016) and is typically focussed on understanding the overall effect at the ecosystem level; with only a limited number of studies undertaking repeated sampling of the same sites. Much less is known about the temporal variability of invader effects on lotic communities. To date, only a few studies have considered the long term effect of signal crayfish on freshwater macroinvertebrate communities (see Wilson et al. 2004; McCarthy et al. 2006; Ruokonen et al. 2016; Mathers et al. 2016) and none have considered intra-annual temporal dynamics at shorter time scales (i.e. multiple months) once an invasive population has become established (i.e. associated with key life history characteristics and crayfish activity levels). Understanding and quantifying the extent of invader effects will continue to be constrained until studies are conducted that span the appropriate spatial and temporal scales (McCarthy et al. 2006).

Community composition of lotic macroinvertebrate populations vary over space and time associated with physical properties such as flow, water quality and the availability of resources, but also demonstrate short term (seasonal) temporal shifts related to individual taxon life histories (Hynes 1972; Beche et al. 2006; Tonkin et al. 2017). Many taxa exhibit seasonal life cycles which are tied to optimal environmental conditions including temperature (Huryn and Wallace 2000), flow (Bunn and Arthington 2002) and food availability (Anderson and Cummins 1979; Murphy and Giller 2000), or to avoid competition via temporal niche separation (Grant and Mackay 1969; Bjelke et al. 2005). Crayfish also display variations in levels of activity, which generally increase with rising water temperatures (Johnson et al. 2014). These changes in macroinvertebrate taxon abundances and crayfish activity levels over time may affect the magnitude of crayfish effects within the invaded ecosystem, particularly if preferential prey items are depleted over the seasonal timeframe when crayfish are active.
The physical habitat template of the ecosystem in which biological invasions take place will most likely control the effect the invader has on the receiving ecosystem. A number of studies have documented highly variable effects of non-native taxa as a function of the physical characteristics of the ecosystem (Vilà et al. 2011; Klose and Cooper 2012). Heterogeneous habitats, which contain boulders and cobbles, macrophytes and interstitial habitat potentially provides refuges for prey items and may reduce the effects of predation compared to areas with low habitat complexity (Crooks 2002). Fine sediment loading can lead to the homogenisation of lotic ecosystems and a loss of habitat (Wood and Armitage 1997), but may also lead to reduced macroinvertebrate diversity through elevated drift or direct burial (Wood et al. 2005; Larson et al. 2010; Jones et al. 2012). Such alterations to resident macroinvertebrate assemblages (in particular species richness) associated with the habitat template may modify the interactions and effects of invasive crayfish on the wider macroinvertebrate community (Fitzgerald et al. 2016).

This study investigated the effect of invasive signal crayfish within a high resolution sampling timeframe. In contrast to other studies, which have examined the net effect of large established populations of crayfish on stream communities via spot sampling throughout the year, this study aimed to examine the temporal variability of crayfish effects (if any) throughout the main period of crayfish activity. We specifically sought to address the following research question-do crayfish effects on the wider macroinvertebrate community intensify as the activity season proceeds or are the effects on the macroinvertebrate community consistent regardless of crayfish activity? Crayfish are cold-blooded and therefore activity levels are strongly associated with water temperature. Consequently, crayfish activity is most pronounced during the summer months and has been reported to cease below $5^{\circ} \mathrm{C}$ (Bubb et al. 2004; Johnson et al. 2014). Given the potential moderation of predator-prey interactions associated with the local physical habitat, the study also considers the role of substrate character, specifically fine sediment content, in influencing invasive crayfish community effects. 


\section{Materials and methods}

\section{Study sites}

The study took place on two small lowland rivers in Rutland (UK); the River Gwash $\left(52^{\circ} 38^{\prime} \mathrm{N}, 00^{\circ} 44 \mathrm{~W}\right)$ and the River Chater $\left(52^{\circ} 37^{\prime} \mathrm{N}, 00^{\circ} 44^{\prime} \mathrm{W}\right)$. Historic routine sampling by the Environment Agency (1989-2015) and contemporary sampling during the study period by the author has not recorded any signal crayfish in the River Chater (control river), whilst density estimates in the Gwash (invaded river) during 2014-2015 indicated a mean catch per unit effort of 4.7 individuals per trap per night $(n=20)$. Both of these rivers formed part of a long-term analysis in which the River Gwash demonstrated a significant divergence in assemblage composition following crayfish invasion (1996) compared to the River Chater (and other control rivers; Mathers et al. 2016). Community composition was historically comparable in both rivers and the divergence in communities associated with crayfish presence has persisted over time. Study sites were selected to be as broadly comparable in physical characteristics (channel size, water chemistry, altitude and geology) as possible and experienced similar hydroclimatological regimes given they were located $2.6 \mathrm{~km}$ apart (Fig. 1).

\section{Colonisation cylinders}

At both sites, colonisation cylinders were deployed which provided a constant record of the macroinvertebrate community. Each colonisation cylinder comprised a PVC cylinder (diameter $65 \mathrm{~mm}$, height $200 \mathrm{~mm}$ ) perforated with twelve horizontal holes (diameter $6 \mathrm{~mm}$ ) to permit horizontal and vertical exchange of flow, macroinvertebrates, and fine sediment (Mathers and Wood 2016). All cylinders were filled with a prewashed gravel framework collected from each of the respective sample sites (truncated at $8 \mathrm{~mm}$ ) that was enclosed in a net bag (7 $\mathrm{mm}$ aperture) within each cylinder.

A second cylinder treatment was deployed to allow investigation of how fine sedimentation of the substratum affects crayfish-macroinvertebrate interactions. In these cylinders, $250 \mathrm{~g}$ of fine sand $(63-2000 \mu \mathrm{m})$ was added to the gravel framework. Preliminary tests indicated that this filled $100 \%$ of the interstitial volume of the substrates. Signal crayfish have the potential to directly alter the input and output of fine sediment, which may have consequences for the in channel storage of fine sediments (Harvey et al. 2011). Crayfish burrowing activities may enhance the delivery of fine sediment (Faller et al. 2016) while the diurnal bioturbation of fine sediment associated with crayfish activity increases sediment fluxes out of the reach and winnows fines (Rice et al. 2016; Albertson and Daniels 2016). It is likely that the relative role of these contrasting processes varies depending on the spatial distribution of crayfish within a river reach and therefore the effect of crayfish on fine sediment loading may not be consistent. Consequently, the application of two sediment treatments in this study (i.e. no fine sediment and interstitial pore space filled with fines) enabled the potential effect of differing fine sediment loading and temporal variability of crayfish effects for the invaded ecosystem to be examined.

For the cylinders with enhanced fine sediment loading (hereafter referred to as clogged), a circular disk (64 mm diameter) was attached to the mesh bag which effectively sealed the base of the cylinder and reduced the loss of fine material vertically into the riverbed. Cylinders were inserted into the river bed by placing the PVC cylinders onto a steel pipe $(35 \mathrm{~mm}$ diameter) that was then driven into the bed sediments by hand until a sufficient sized hole was formed. Cylinders were inserted flush with the sediment surface to a depth of $200 \mathrm{~mm}$ and left in situ for the entire sampling campaign. Every 14 days, the gravel netting bag was removed and replaced with fresh gravel, providing an ongoing record of the macroinvertebrate communities at this resolution. At the end of each 14-day sampling period, the net bag was carefully removed and placed directly into a sample bag. Empty cylinders were then replaced with the corresponding gravel bag treatment (clean or clogged). All invertebrate samples were preserved in the field in $10 \%$ formaldehyde and returned for the laboratory for processing and identification.

Colonisation cylinders were installed for 126 days providing nine 14-day sample sets (21st May-24th September 2015). At each riffle site (three sites at the invaded reach and two sites at the control; one until 2nd July 2015), four cylinders of each type (clean or clogged) were installed providing a total of 12 replicates in the invaded site and 8 (4 initially for 3 sample sets) at the control. In total, 213 and 112 


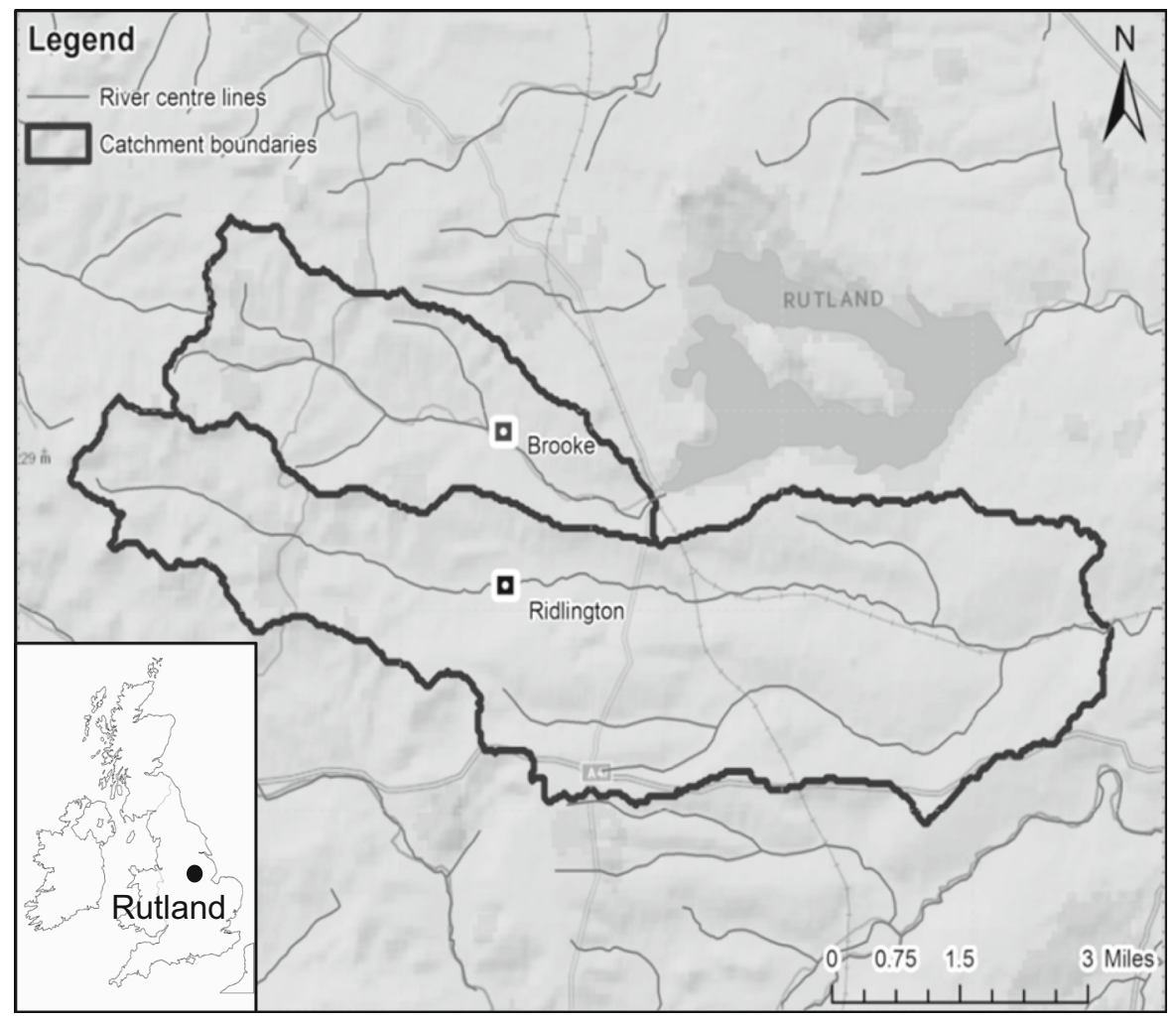

Fig. 1 Location of study sites on the River Chater (Ridlington, control) and River Gwash (Brooke, invaded), Rutland, UK

Table 1 Summary of datasets collected for this study at the invaded (Gwash) and control (Chater) rivers during 2015

\begin{tabular}{lllll}
\hline Sample set & Dates covered & Invaded & & Control \\
\cline { 3 - 4 } & & Colonisation cylinders & Crayfish trapping & Colonisation cylinders \\
\hline 1 & 21st May-4th June & $\mathrm{n}=23$ & $\mathrm{n}=1$ & $\mathrm{n}=7$ \\
2 & $\mathrm{n}=24$ & $\mathrm{n}=1$ & $\mathrm{n}=7$ \\
3 & $\mathrm{n}=24$ & $\mathrm{n}=1$ & $\mathrm{n}=8$ \\
4 & 4th June-18th June & $\mathrm{n}=24$ & $\mathrm{n}=1$ & $\mathrm{n}=16$ \\
5 & 18th June-2nd July & $\mathrm{n}=23$ & $\mathrm{n}=2$ & $\mathrm{n}=15$ \\
6 & 2nd July-15th July & $\mathrm{n}=24$ & $\mathrm{n}=2$ & $\mathrm{n}=14$ \\
7 & 15th July-30th July & $\mathrm{n}=24$ & $\mathrm{n}=3$ & $\mathrm{n}=15$ \\
9 & 30th July-13th August & $\mathrm{n}=23$ & $\mathrm{n}=3$ & $\mathrm{n}=16$ \\
\hline
\end{tabular}

For each of the crayfish trapping replicates (n), a number of traps were set within the study reach (average of six per occasion)

substrate samples were examined from the invaded and control sites respectively (3 clean cylinders were not retrieved from both sites and 5 clogged cylinders were lost at the control site; Table 1 provides a breakdown of sample dates and riffle replicates over time). 
Crayfish activity

Trapping was conducted on an intermittent basis throughout the sampling campaign as a surrogate for adult crayfish activity (see Table 1 for a breakdown of trapping occasions). Periodically $(\mathrm{n}=15)$, baited "trappy" traps $(50 \times 20 \mathrm{~cm}$ with an opening of $5 \mathrm{~cm}$ and mesh size $3 \mathrm{~cm}$ ) were deployed at the invaded site at three locations throughout the reach (upstream, middle and downstream). This sampling strategy enabled a spatially representative record of activity levels as crayfish are known to move sporadically to new locations and therefore not reside at a single location (Bubb et al. 2002). On each occasion traps were set at a location during the afternoon and retrieved the following morning with a minimum of two traps per location. Catch Per Unit Estimates (CPUE) were calculated from the total number of adult individuals caught for each sampling set and presented as an abundance index. Trapping often leaves juvenile crayfish population's uncharacterised (Holdich et al. 1999), however juvenile crayfish were regularly recorded in the colonisation cylinders. This provided a means of assessing the relative abundance of juvenile crayfish during the survey season. The number of juvenile crayfish recorded in the cylinders for each sample set was standardised to the number of individuals per $\mathrm{m}^{2}$ by dividing the total number of crayfish for each sample set by the total sample surface area of the cylinders $\left(\mathrm{ind} / \mathrm{m}^{2}\right)$.

Laboratory procedures and statistical analysis

Within the laboratory, samples were processed for invertebrates by passing the cylinder samples through a series of sieves $(4 \mathrm{~mm}, 2 \mathrm{~mm}$ and $250 \mu \mathrm{m})$. All macroinvertebrates were identified to the lowest taxonomic level possible, which was usually species or genus with the exception of Oligiochetea (order), Diptera families (including Ephydridae, Ptychopteridae, Chironomidae, Psychodidae, Simuliidae, Ceraptogonidae and Stratiomyidae), Sphaeriidae and Zonitidae (family) and Ostracada, Hydracarina and Collembola which were recorded as such.

To identify temporal changes in macroinvertebrate communities associated with crayfish activity and species life-cycles, non-metric multidimensional scaling (NMDS) centroid plots were employed over time for the invaded and control sites (sample sets 1-9).
Distances among centroid matrices were constructed by calculating the averages (e.g. the centroid-the centre-point of all replicates for each sample set in multi-dimensional space) using Bray-Curtis similarity coefficients (Anderson et al. 2008). Compositional differences in communities between the control and invaded sites were examined using non-metric multidimensional scaling (NMDS) plots using Bray-Curtis similarity coefficients for the overall data set and for each individual sample set. This approach enabled examination of whether community effects were temporally similar or whether they varied over time.

A One way ANOSIM (Analysis of Similarities) was used to examine differences in the communities amongst the control and invaded rivers for the overall data set and for each sample set (1-9). For each dataset, a random Monte Carlo permutations test was performed (999 random permutations). Both $\mathrm{P}$ and $\mathrm{R}$ ANOSIM values were examined, with $R$ values $>0.75$ indicating strong separation amongst groups, $\mathrm{R}=0.75-0.25$ indicating separate groups with overlapping values and $\mathrm{R}<0.25$ as barely distinguishable groups (Clarke and Gorley 2006). To examine if invaded or control communities were more or less heterogeneous than the other, homogeneity of multivariate dispersions (beta diversity) between aquatic macroinvertebrate assemblages based on Bray-Curtis distance matrices from the centroid were calculated using the PERMDISP function and compared using One-Way ANOVA (Anderson 2006; Anderson et al. 2006, 2008). Taxa contributing to the divergence of communities were identified through the application of the similarity percentage (SIMPER) with a number of these in addition to those that have been cited in previous literature associated with crayfish invasions, selected for further statistical analysis. All ordination analyses were performed in PRIMER Version 7.0.11 (PRIMER-E Ltd, Plymouth, UK).

Community abundance and taxa richness metrics were derived from the raw data, in addition to richness of Ephemeroptera, Plecoptera and Trichoptera (EPT) groups. To examine differences in macroinvertebrate metrics and individual taxon abundances associated with crayfish presence, generalised linear mixed effects models were developed (GLMMs). Models were fitted using the 'Ime4' package in R version 3.2.2 using the 'glmer' function ( $\mathrm{R}$ Development Core Team 2014). To examine differences associated with the volume of fine sediment, treatment was specified 
as a fixed factor and riffle was nested within site as a random factor (columns within individual riffles and sites are less independent of each other). Models were fitted using a Poisson error distribution and log link structure.

\section{Results}

Community composition associated with crayfish presence and sediment treatment

A total of 69 taxa were recorded from the 169 colonisation cylinders; of these 57 were recorded in the invaded river (mean 6.62, range 1-14) and 54 in the control river (mean 7.06, range 2-16). In all, 17,734 individuals were recorded from the nine sampling sets (invaded river mean 55.02, range 14-168; control river mean 54.68, range 9-136). Communities at the invaded site were dominated by Gammarus pulex (56.69\% of total abundance), Chironomidae larvae (14.10\%) and Potamopyrgus antipodarum (9.92\%). The most abundant taxa at the control site were Gammarus pulex $(69.70 \%$ of total abundance), Oligochaeta (5.63\%) and Chironomidae $(4.66 \%)$.

Non-metric Multi-Dimensional Scaling (NMDS) ordination diagrams for the entire dataset and the nine individual sampling sets indicated distinct clusters of macroinvertebrate communities at the invaded and control river on all occasions (Fig. 2). The degree of separation between the groups remained consistent over time with all sample sets indicating highly significant differences for all pairwise comparisons (ANOSIM; eight of nine sets and global dataset $p \leq 0.001$ and set $2 p=0.002$; Table 2).

When sediment treatment was considered, the crayfish invaded site had a different macroinvertebrate community composition compared to the control site. However, it was also evident that there were significant differences between sediment treatments which were distinct for both the control and invaded sites. Four distinct clusters were evident in the ordination plots as a function of the presence of crayfish and substrate treatment (Fig. 3; only one sampling period, set 4 , is shown for conciseness, for all sampling periods see Figure S1), and in all instances these differences were statistically different (ANOSIM all $p$ values $<0.003$; Table $\mathrm{S} 1$ ). Clean substrate communities demonstrated the greatest separation between invaded and control communities with all pairwise comparisons being significant compared to 7 out of the 9 clogged sets (Table 2).

Both the invaded and control site demonstrated comparable trajectories of assemblage change over time (Fig. 4). However, the change in composition over time remained consistent at the control site, whilst Sets $4-8$ at the invaded site cluster together followed by another shift in composition for Set 9 . Multivariate dispersion indicated a shift in the heterogeneity of the communities over time. Invaded communities demonstrated similar beta diversity to the control site for the first three sample sets (average distance for invaded 29.30 and 29.04 for control communities), after which control communities displayed greater heterogeneity (sets 4-9; control site average distance 31.58 ) with invaded sites demonstrating a noticeable reduction in beta diversity (average distance 28.17). Only Set 4 of the pairwise distances was determined to be significantly different ( $\mathrm{T}=3.13, p=0.008$; Table 3). When the global dataset was considered, the control site was significantly more heterogeneous $(\mathrm{T}=3.77, p=0.001)$ than the invaded site (average distances 34.44 control and 31.21 invaded). The top ten taxa driving dissimilarity overall between control and invaded sites were Chironomidae $(5.65 \%$ dissimilarity), Oligochaeta (5.11\%), P. antipodarum (5.03\%), G. pulex (4.26\%), Erpobdella octoculata (3.81\%), Dicranota sp. (2.81\%), Habrophlebia fusca $(2.79 \%)$, Baetis sp. (2.29\%), Elmis aenea (adult; $2.01 \%$ ) and Sphaeriidae (1.90\%).

Community metrics and individual taxon abundances associated with crayfish presence

Total community abundance did not vary significantly by site or time $(p>0.05)$. Taxa richness varied significantly over time $\left(\mathrm{Z}_{10,320}=-3.64, p<0.001\right)$ and displayed a significant site: time interaction $\left(\mathrm{Z}_{10,320}=2.17, p=0.03\right)$ with lower numbers of taxa on most sampling occasions at the invaded site (Fig. 5). EPT abundance and richness varied over time (both $p<0.001$ ) but not by site $(p>0.05$ ).

When individual taxon abundances were considered, the Hirudinea species, E. octoculata, displayed consistently lower abundances at the invaded site $\left(\mathrm{Z}_{10,320}=2.03, \quad p=0.043 ; \quad\right.$ Fig. 6a $)$. Mollusca 


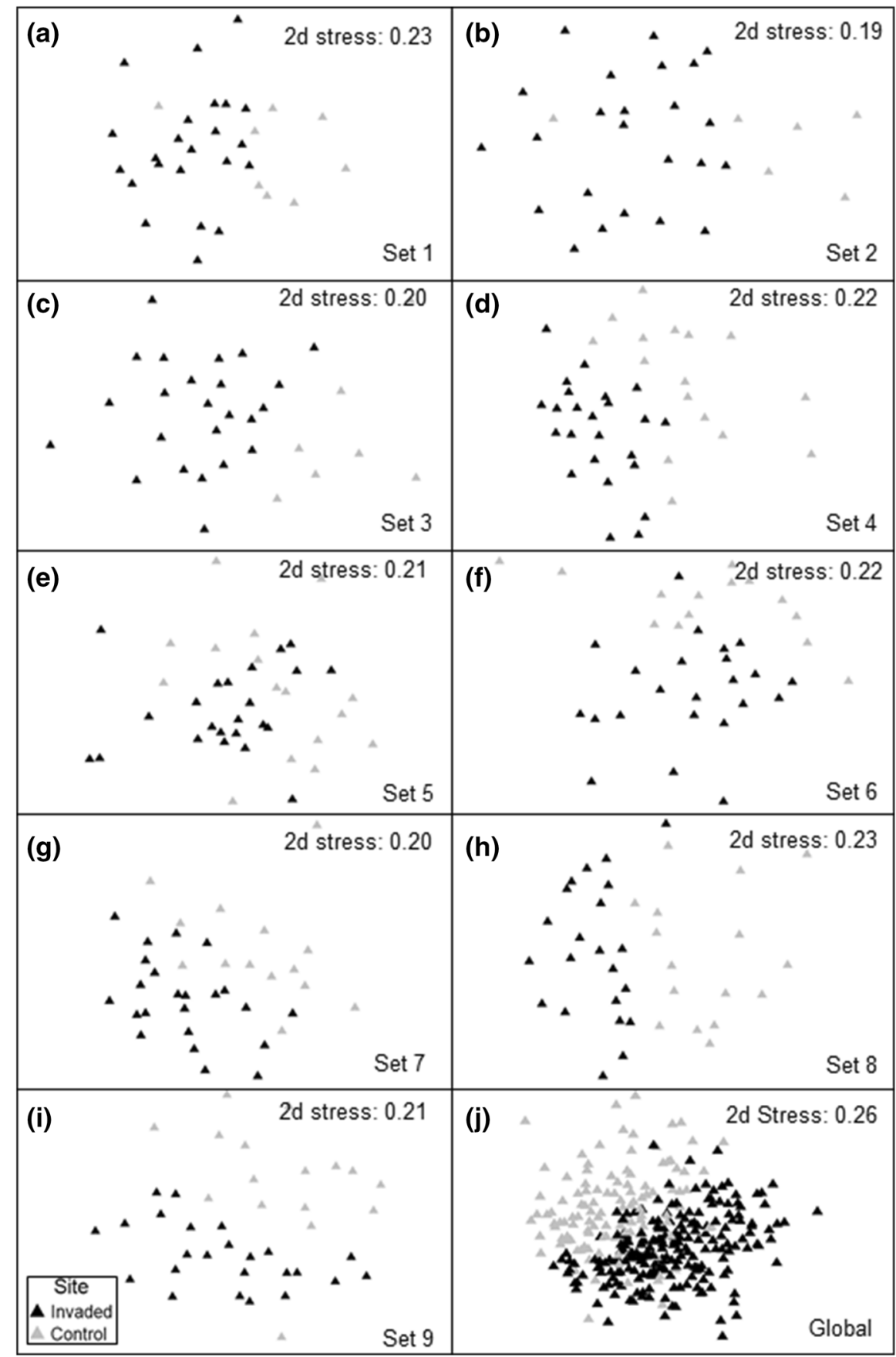

Fig. 2 Non-metric multidimensional scaling (NMDS) of macroinvertebrate community data using the Bray-Curtis similarities coefficients for cylinder sets 1-9 (a-i; 21st May24th September 2015) and global data set (j). Black triangles $=$ invaded $($ Gwash) and grey triangles $=$ control (Chater). For a breakdown of sampling dates for the individual sample sets see Table 1 
Table 2 Summary of ANOSIM values over time by crayfish presence and sediment treatment

\begin{tabular}{|c|c|c|c|c|c|c|}
\hline \multirow[t]{2}{*}{ Set } & \multicolumn{2}{|c|}{ Site differences } & \multicolumn{2}{|c|}{ Clean versus clean } & \multicolumn{2}{|c|}{ Clog versus clog } \\
\hline & $\mathrm{r}$ value & $p$ value & $\mathrm{r}$ value & $p$ value & $\mathrm{r}$ value & $p$ value \\
\hline 1 & 0.325 & 0.001 & 0.409 & 0.018 & 0.249 & 0.078 \\
\hline 2 & 0.407 & 0.002 & 0.545 & 0.006 & 0.116 & 0.363 \\
\hline 3 & 0.552 & 0.001 & 0.812 & 0.002 & 0.402 & 0.012 \\
\hline 4 & 0.417 & 0.001 & 0.424 & 0.001 & 0.524 & 0.001 \\
\hline 5 & 0.252 & 0.001 & 0.413 & 0.001 & 0.208 & 0.015 \\
\hline 6 & 0.306 & 0.001 & 0.348 & 0.001 & 0.340 & 0.004 \\
\hline 7 & 0.367 & 0.001 & 0.368 & 0.002 & 0.277 & 0.016 \\
\hline 8 & 0.375 & 0.001 & 0.399 & 0.001 & 0.394 & 0.030 \\
\hline 9 & 0.411 & 0.001 & 0.281 & 0.006 & 0.487 & 0.001 \\
\hline Global & 0.342 & 0.001 & 0.306 & 0.001 & 0.306 & 0.001 \\
\hline
\end{tabular}

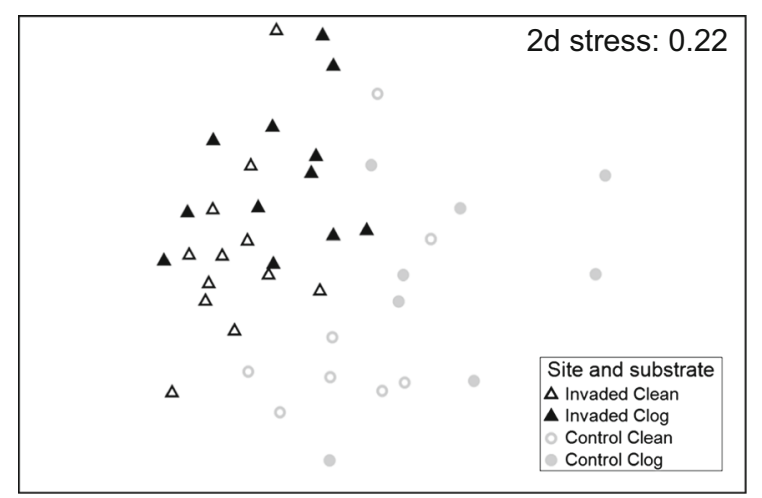

Fig. 3 Non-metric multidimensional scaling (NMDS) of macroinvertebrate community data using the Bray-Curtis similarities coefficients for cylinder sampling set 4 (2nd-15th July 2015) as a function of combined crayfish presence/absence and sediment treatment (clean or clogged). Black open triangles $=$ invaded clean substrates; black solid triangles $=$ invaded clog substrates; grey open circles $=$ control clean substrates and; grey solid triangles $=$ control clog substrates

responses varied, with $P$. antipodarum displaying greater abundances at the invaded site on a number of occasions (Site: time interaction $\mathrm{Z}_{10,320}=-2.35$, $p=0.019$; Fig. 6b) whilst Sphaeridae was recorded in greater numbers at the control site $\left(Z_{10,320}=3.427\right.$, $p<0.001)$ and varied over time $\left(\mathrm{Z}_{10,320}=3.56\right.$, $p<0.001)$ and demonstrated a site: time interaction $\left(\mathrm{Z}_{10,320}=-3.16, p=0.002\right)$. Dicranota sp. demonstrated significant differences in abundances associated with site $\left(\mathrm{Z}_{10,320}=-3.38, p<0.001\right.$; Fig. 6c) and over time $\left(\mathrm{Z}_{10,320}=-13.61, p<0.001\right)$. The coleopteran family Elmidae (comprising multiple species; Limnius volckmari, Elmis aenea and Oulimnius sp.) were recorded in significantly greater

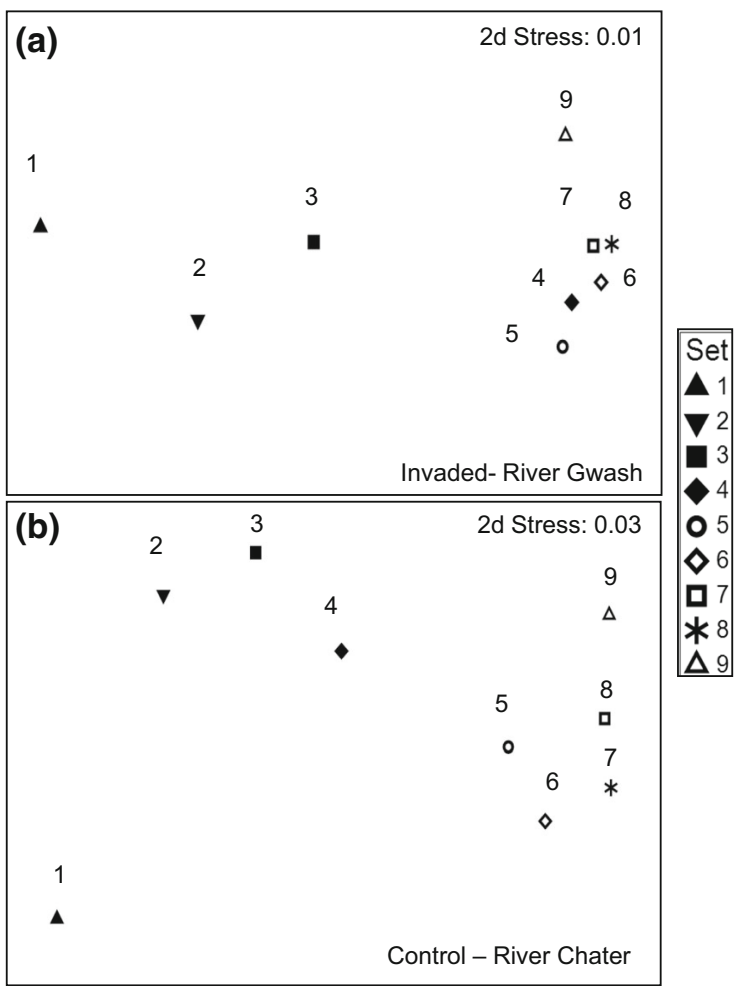

Fig. 4 Non-metric multidimensional scaling (NMDS) temporal centroid ordinations of community data for cylinder sets 1-9 (21st May-24th September 2015) at: a River Gwash and; b River Chater. For a breakdown of sampling dates for the individual sample sets see Table 1

abundances at the control site in both larval $\left(\mathrm{Z}_{10,320}=2.49, p=0.013\right)$ and adult life stages $\left(\mathrm{Z}_{10,320}=3.178, p=0.001\right)$ with the effect consistent across the entire sampling period (Fig. 6d). Crayfish presence did not affect all taxa within the 
Table 3 Summary of PERMDISP analysis by crayfish presence. Significant results are emboldened

\begin{tabular}{llll}
\hline Set & \multicolumn{2}{l}{ Average distance } & $p$ value \\
\cline { 2 - 3 } & Invaded & Control & \\
\hline 1 & 28.18 & 27.53 & 0.852 \\
2 & 30.23 & 29.69 & 0.856 \\
3 & 29.61 & 29.90 & 0.956 \\
4 & 26.04 & 32.02 & $\mathbf{0 . 0 0 8}$ \\
5 & 27.62 & 31.62 & 0.224 \\
6 & 28.08 & 29.74 & 0.561 \\
7 & 28.31 & 31.66 & 0.223 \\
8 & 27.36 & 30.78 & 0.129 \\
9 & 31.60 & 33.67 & 0.438 \\
Global & 31.21 & 34.44 & $\mathbf{0 . 0 0 1}$ \\
\hline
\end{tabular}

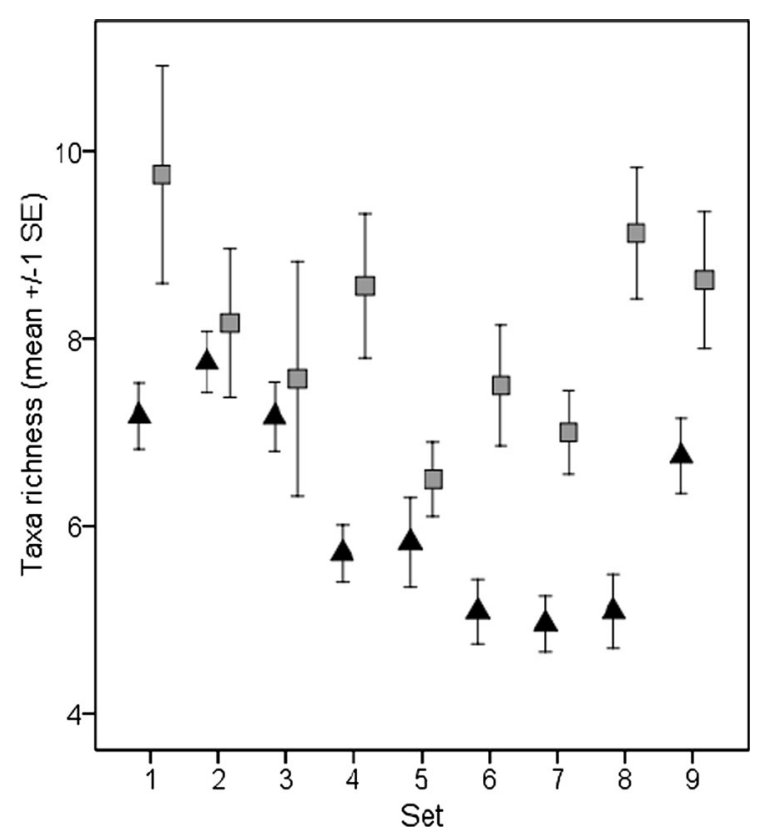

Fig. 5 Mean ( \pm 1 SE) a) taxa richness over the nine sample sets (21st May-24th September 2015). Black triangles $=$ invaded communities and grey squares $=$ control communities. For a breakdown of sampling dates for the individual sample sets see Table 1

order of Ephemeroptera. The crawler H. fusca demonstrated significantly lower abundances on a number of sampling occasions at the invaded site with abundances being significantly lower during sampling set 3 (Site: time 3 interaction $\mathrm{Z}_{10,310}=3.6, p<0.001$;
Fig. 6e), while the swimming taxa Baetis sp. demonstrated no significant difference between the invaded and control site but did vary in abundance over time $\left(\mathrm{Z}_{10,320}=-9.67, p<0.001\right.$; Fig. $\left.6 \mathrm{f}\right)$.

Signal crayfish activity

A total of 25 juvenile signal crayfish were recorded in the cylinders over the course of the sampling campaign. Individuals first appeared in the sampling record in Set 2 (early June), which also corresponded to the greatest abundance of individuals (12 ind $=150.5 \mathrm{ind} / \mathrm{m}^{2}$ ). Individuals were recorded in each set until sampling period 7 (late August), with a second peak being evident during set 5 (late July; 82 ind $/ \mathrm{m}^{2}$; Fig. 7). There was no apparent preference displayed for clean or clogged substrates (22.3 and 24 $\mathrm{ind} / \mathrm{m}^{2}$ respectively).

Trapping of the adult component of the population indicated temporal differences in the number of individuals trapped (average 3.9 adults, range $0-5.55$ CPUE; Fig. 8). No crayfish were trapped during Set 1 and were recorded in low abundances during Set 3. Set 2 recorded large CPUE numbers similar to those recorded during Sets 4-9 and corresponded to the first occurrence of juvenile crayfish (young-of-year) in the cylinders.

\section{Discussion}

Crayfish effects for macroinvertebrate communities-temporal evolution during the summer months

The results from this study demonstrate that invasive signal crayfish have significant and persistent effects on the wider lotic macroinvertebrate community regardless of their activity levels. NMDS ordination analysis indicated distinct differences in the communities at invaded and control sites throughout the sampling period (21st May-24th September) and for each of the nine individual 14-day sampling sets. All pairwise comparisons were determined to be highly significant (all $p<0.002$ ) demonstrating the strong and persistent modifications to macroinvertebrate assemblages once invaded (Wilson et al. 2004; McCarthy et al. 2006). Crayfish also had a significant effect on beta diversity, with control communities 
Fig. 6 Mean abundances ( \pm 1 SE) of a Erpobdella octoculata; b Potamopyrgus antipodarum; c Dicranota sp.; d Elmidae adult; e Habrophlebia fusca and; f Baetis sp. over the nine sample sets. Black triangles $=$ invaded communities and grey squares $=$ control communities. For a breakdown of sampling dates for the individual sample sets see Table 1
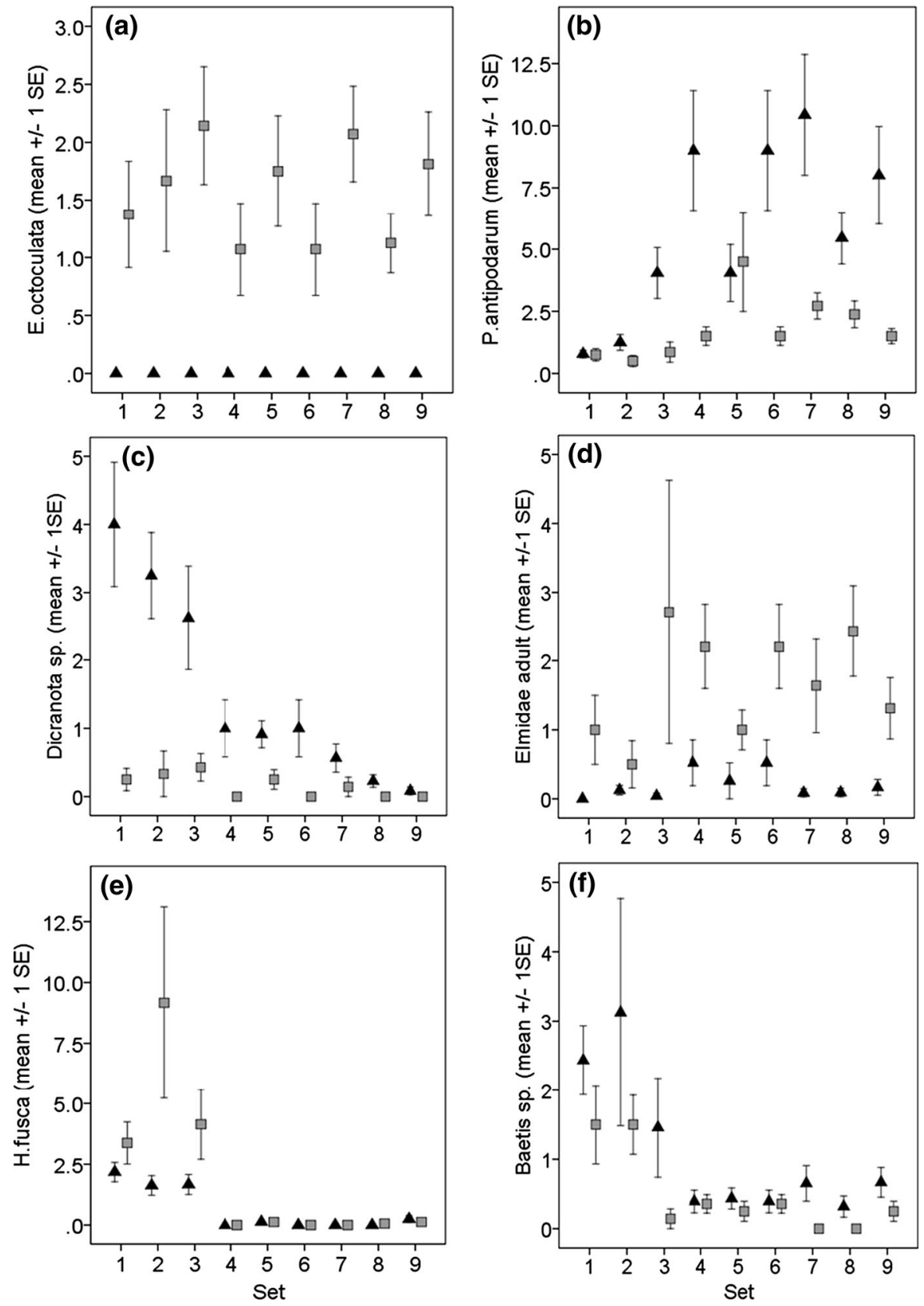

demonstrating a greater degree of community heterogeneity compared to those at the invaded site. When the temporal community effects and activity of crayfish were considered, both invaded and control communities demonstrated similar temporal trajectories of change reflecting natural variability in macroinvertebrate assemblages as a function of taxon life histories (Johnson et al. 2012). However, invertebrate communities at the invaded crayfish site demonstrated some variations most likely reflecting modifications in crayfish activity levels over the sampling period.

During the first three sets of samples (late Mayearly July) both rivers demonstrated similar temporal changes and there was therefore some evidence to suggest that community effects were less marked following prolonged periods of lower water temperatures (i.e. over winter and early spring). Both invaded and control sites also displayed similar community 


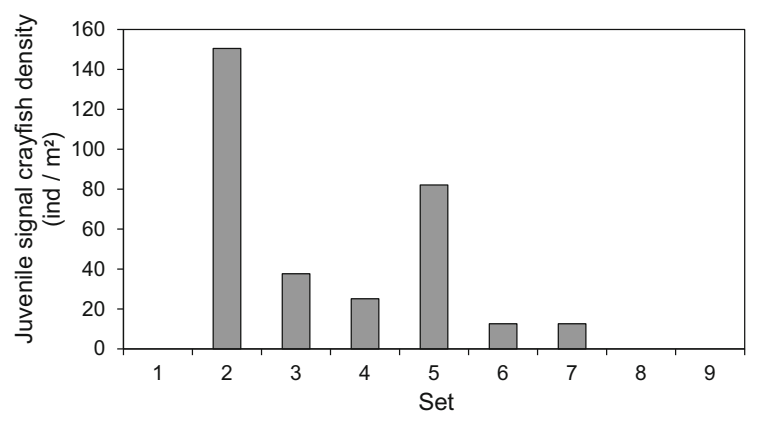

Fig. 7 Density of juvenile signal crayfish recorded during individual sampling sets (21st May-24th September 2015) via the colonisation cylinders at the invaded site (Gwash). For a breakdown of sampling dates for the individual sample sets see Table 1

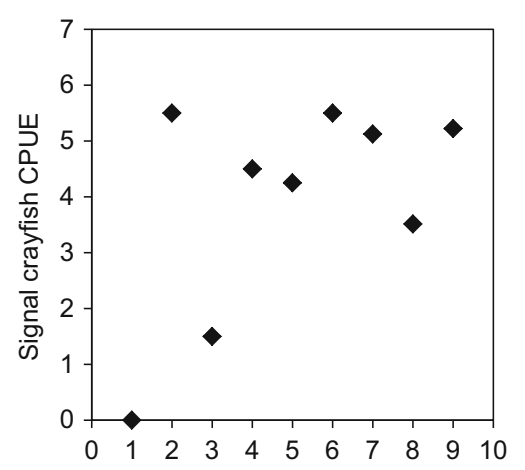

Fig. 8 Adult signal crayfish catch per unit effort (CPUE) for each sample set at the invaded site (Gwash). For a breakdown of sampling dates for the individual sample sets see Table 1

heterogeneity during the early surveys (set 1-3) when adult crayfish activity was low (as determined by CPUE; although set 2 probably coincided with the release of young-of-year). However, Set 4 (early July) represents a discrete period during which the community trajectory differed markedly between control and invaded sites. At the invaded site, communities' clustered together during Sets 4-8 (early July-Mid September), whilst at the control site, the assemblage continued to demonstrate greater variability over time. This period coincides with increased adult crayfish activity associated with elevated water temperatures (average temperature of $14.7{ }^{\circ} \mathrm{C}$ compared to $13.7^{\circ} \mathrm{C}$ in the preceding months; Fig. 9; Bubb et al. 2006). CPUE abundances increase considerably during Set 4 and remained consistently high throughout the remainder of the sampling campaign. Consequently, it is likely that despite crayfish having significant and ongoing effects for the wider macroinvertebrate community, there were small scale differences over time. Notably, the only sample set to demonstrate significant differences in beta diversity between invaded and control rivers was Set 4 , coinciding with the period when crayfish activity intensified.

From mid to late September (Set 9) there was a second shift in temporal community composition, potentially reflecting changes in crayfish behaviour, with this time period coinciding with the start of the mating season (Lewis 2002). The high temporal resolution dataset utilised in this study potentially enables the key stages in crayfish activity and their lifecycle to be identified. This study was conducted in a river which supported a well-established and abundant crayfish population ( $>20$ years) and thus the overwhelming effect of crayfish presence is such that community composition has been modified (sensu Mathers et al. 2016). The life cycle/history characteristics of crayfish populations (increased activity in late spring and during mating) may have even more marked effects on invertebrate populations in rivers where the invasion is more recent or abundances are low as a result of preferential prey taxa (e.g. Hirudinea and Gastropoda) still being present at relatively high abundances.

The role of substrate character and crayfish presence on macroinvertebrate communities

When sediment treatment was considered, community effects of invasive crayfish presence were most pronounced within the clean substrates (evidenced in the ANOSIM values), but were still evident within the clogged substrates. Clean substrates are widely acknowledged to support a greater diversity of macroinvertebrates (Richards and Bacon 1994; Wood and Armitage 1999; Growns et al. 2016) and are therefore more likely to demonstrate a more marked effect of sustained crayfish predation associated with their initial higher taxa richness. In marked contrast, homogenous substrates (i.e. fine sediment dominated environments), which are typically species poor, may experience less significant effects following crayfish invasion as a function of the lower initial taxa richness.

Within boreal lakes, Ruokonen et al. (2014) documented habitat specific effects of signal crayfish for resident macroinvertebrate taxa. It is likely that the effects of crayfish invasion will vary dependent on 


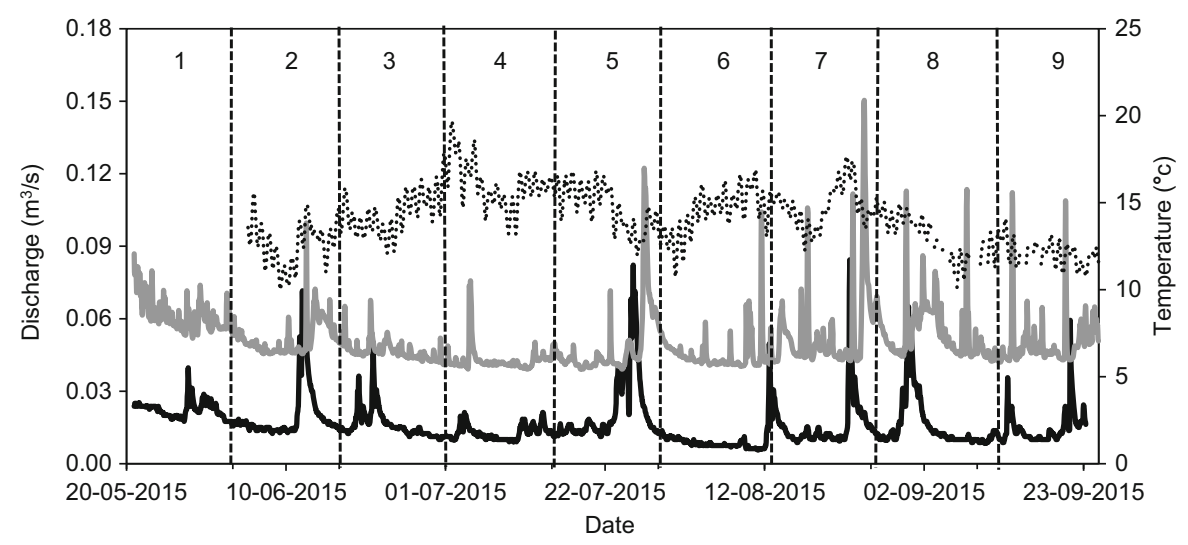

Fig. 9 River discharge (hourly average $\mathrm{m}^{3} \mathrm{~s}^{-1}$ ) for the River Gwash (black) and River Chater (grey) Rutland, UK during the sampling campaign from gauging stations (Manton $52^{\circ} 38^{\prime} \mathrm{N}$, $00^{\circ} 42^{\prime} \mathrm{W}$ and Fosters Bridge, $\left.52^{\circ} 36^{\prime} \mathrm{N}, 00^{\circ} 30^{\prime} \mathrm{W}\right)$. Dotted black represents water temperature recorded on the River Gwash (hourly averaged). The river Chater temperature is a parallel

local habitat conditions which act as a physical template for resident taxa. Consequently, the effects of invasive species should be evaluated across a range of relevant habitats and spatial scales in order to enable the extent of invader effects to be quantified. Nevertheless, the results from this study indicate that when substrate conditions are considered, the effects of invasive crayfish were stronger and more consistent than the differences in communities associated with the volume of fine sediment present. That is, macroinvertebrate communities demonstrate a consistent and highly significant difference in composition as a function of the established invasive crayfish populations regardless of the substrate conditions.

Taxa-crayfish interactions

Crayfish presence did not significantly affect total macroinvertebrate abundance within this study. The effect of crayfish presence on invertebrate densities is highly variable with some studies indicating a reduction (Nyström 1999; Crawford et al. 2006) whilst others have reported no differences (Lagrue et al. 2014; Ercoli et al. 2015a). The inconsistent results suggest that any effect on total community abundances is weak and probably a function of original community composition, and highly dependent on individual species responses. Within this study, taxa richness was significantly lower at the invaded site compared to the control site. This effect remained consistent series and is therefore not presented. Dashed lines indicate the 2 week sampling periods (21st June-24th September 2015). Temperature data is not available until 4th July due to equipment failure. For a breakdown of sampling dates for the individual sample sets see Table 1

throughout the sampling period, but was not as marked during sets 2 and 3, a factor reflected in the site: time interaction. Reduced taxa richness has also been documented in a number of other studies following signal crayfish invasion (e.g. Crawford et al. 2006; Ruokonen et al. 2014; Ercoli et al. 2015a, b).

When individual species were considered, the most widely cited taxa affected by crayfish invasion were the class of Hirudinea (leeches), which typically demonstrate significant reductions in abundance (Stenroth and Nyström 2003; Crawford et al. 2006). The unprotected soft bodies and relative slow mobility of these taxa make them ideal prey items for crayfish (Stenroth and Nyström 2003). Results from this study provide further evidence to support this finding, with only 11 individuals in this class being recorded at the invaded site during the entire sampling period (control site $=205$ individuals). Moreover, one Hirudinea species, Helobdella stagnalis was unique to the control site. E. octoculata, the most abundant taxon in this class, occurred at low abundances throughout the sampling period with no temporal variation in numbers evident.

Another group of taxa which are typically associated with reductions in density, biomass and richness following invasive crayfish population establishment are Mollusca (Weber and Lodge 1990; Lodge and Hill 1994; Dorn 2013). Similar to Hirudinea, their reduced rate of mobility makes them susceptible to predation. 
However, the effects recorded varied depending on the species considered, which most likely reflects varying life history characteristics and the ability to adapt behaviours that reduces the threat of predation. A number of species have been documented as demonstrating reduced reproductive rates whilst enhancing their growth rates (Hoverman et al. 2005), whilst others display avoidance behaviour by migrating to the waterline for several hours in the presence of crayfish (Alexander and Covich 1991a, b; Turner et al. 1999).

The latter strategy of avoidance has been recorded for $P$. antipodarum under experimental conditions (Haddaway et al. 2014) and may explain the ability of this species to maintain populations that are even greater than those at the control site within this study. This non-native taxon is tolerant of fine sediment and typically burrows into fine sediment deposits (Holomuzki and Biggs 2000; Suren 2005), a factor which may also facilitate predation evasion. In contrast, bivalves from the family Sphaeriidae were recorded in greater numbers at the control site, although there was a significant site: time interaction with the effect not being consistent over time.

Nyström (1999) suggested that benthic sediment dwelling taxa may dominate crayfish communities. Within this study, in addition to P. antipodarum, both Chironomidae and Dicranota sp., which have a high affinity for fine sediment deposits, were recorded in greater abundances at the invaded site (Fitter and Manuel 1986). Dicranota sp. had high initial abundances at the start of the study, when crayfish activity was minimal, but then displayed a marked reduction in numbers during the remaining sampling events. This taxon has a soft unprotected body similar to Hirudinea and may therefore still be susceptible to predation indicating the importance of considering temporal dynamics associated with faunal life cycles in biological invasion studies.

Within this study, the abundance of the coleopteran family Elmidae was also reduced at the invaded site for both larval and adult life stages. Despite being relatively mobile, the semivoltine life cycle (taking more than 1 year to complete its life cycle) of this taxa makes them more susceptible to disturbances (Elliott 2008) and may therefore make them more vulnerable to predation than other mobile taxa. Gut analysis led Guan and Wiles (1998) to conclude that Coleoptera made up a large component of lotic signal crayfish diets and a number of field studies in lentic environments have suggested that the presence of Elmidae may indicate an absence of crayfish (Bjurström et al. 2010; Ruokonen et al. 2014, 2016).

Taxa in the order of Ephmeroptera have also attracted considerable attention when examining crayfish effects on macroinvertebrate communities with highly variable responses being documented (Mathers et al. 2016). Reductions in abundances (McCarthy et al. 2006) through to no change or enhanced abundances have been reported (Keller and Ruman1998; Usio and Townsend 2004). In this study, contrasting effects were recorded for the swimming mayfly larvae Baetis sp. and the crawling taxon $H$. fusca. These differences most likely reflect the mode of locomotion with swimmers (Baetis) demonstrating enhanced mobility and are therefore able to evade predation more readily by swimming out of the way. In contrast crawlers (H. fusca) display slower locomotion (Peckarsky 1996), typically inhabiting pools and margin areas (Elliott et al. 1988), which may make them more vulnerable to predation by larger crayfish, which also favour pools (Clark et al. 2013).

Application of colonisation cylinders in the monitoring of juvenile crayfish populations

This study used colonisation cylinders to obtain a quantitative record of benthic macroinvertebrate communities over the 126 day study period. Initial deployment of the cylinders occurred before the main period of crayfish activity (late May) when water temperatures were low (average $12.78^{\circ} \mathrm{C}$ ) and therefore provided an opportunity to assess the ability of the method to quantitatively monitor juvenile crayfish abundances, which are notoriously difficult to sample (Moorhouse and Macdonald 2011). Results suggest that colonisation cylinders may be an appropriate technique to determine abundances of juvenile crayfish throughout the sampling period, with peak densities occurring during late June in this study but further testing is required to assess the wider transferability of such an approach. Egg hatching of signal crayfish occurs between late March and the end of July dependent on water temperatures, and it is likely that this peak in numbers reflects the time when eggs were released in this population. The densities recorded during this time frame were $150.5 \mathrm{ind} / \mathrm{m}^{2}$ and reflects 
the high fecundity of this species which make them successful invaders (Kouba et al. 2015).

Densities remained high $\left(37-25 \mathrm{ind} / \mathrm{m}^{2}\right)$ during the following 4 weeks, with a second peak in juvenile abundances in Set 5 (mid July; $82 \mathrm{ind} / \mathrm{m}^{2}$ ). Abundances declined over the next 4 weeks, with no juveniles recorded in the cylinders during the final two sample sets (September). This decline and absence at the end of the study may reflect intraspecific predation of adults upon juveniles (Guan and Wiles 1998) but could also reflect the rapid growth rates of signal crayfish and therefore larger body sizes at this stage inhibiting access to the subsurface substrates. The high number of juvenile crayfish recorded in this study indicates that interstitial habitats are a refuge for juvenile crayfish and an absence of such habitat (i.e. a lack of hyporheic zone within urbanised rivers) may limit the reproductive successes of crayfish populations through reduced survivorship.

Wider applicability of the study

The results of this study suggest that in addition to the major changes recorded in previous studies; changes to the macroinvertebrate community are dynamic reflecting short term temporal patterns. These are probably a function of key environmental controls (water temperate) and life history characteristics (of the invader and resident taxa) such as the timing of reproduction. Although in this study, changes over time were relatively modest, most likely associated with the well-established and abundant crayfish population which had significantly modified the resident communities prior to the current study, the variability recorded at newly invaded or sparsely populated communities may be more marked. The effect of crayfish presence within this river was so strong that changes in the community were evident regardless of substrate conditions and the effect of sedimentation and crayfish therefore resulted in distinct macroinvertebrate communities within each river.

Acknowledgements KLM acknowledges the support of a Glendonbrook doctoral studentship and co-funding from the Environment Agency to undertake this study. Thanks go to Matthew Hill who provided assistance with the fieldwork collection, Richard Harland for providing technical and laboratory support and Samuel Dixon for help in the collection of substrate. Daniel Green is thanked for his help in the preparation of the locational map. Two anonymous reviewers are thanked for their comments which improved the clarity of the manuscript.

Open Access This article is distributed under the terms of the Creative Commons Attribution 4.0 International License (http:// creativecommons.org/licenses/by/4.0/), which permits unrestricted use, distribution, and reproduction in any medium, provided you give appropriate credit to the original author(s) and the source, provide a link to the Creative Commons license, and indicate if changes were made.

\section{References}

Albertson LK, Daniels MD (2016) Effects of invasive crayfish on fine sediment accumulation, gravel movement, and macroinvertebrate communities. Freshw Sci 35:644-653

Alexander JE, Covich AP (1991a) Predation risk and avoidance behaviour in two freshwater snails. Biol Bull 180:387-393

Alexander JE, Covich AP (1991b) Predation avoidance behaviour by the freshwater snail Physella virgate in response to the crayfish Procambarus simulans. Oceologia 180:435-442

Anderson MJ (2006) Distance-based tests for homogeneity of multivariate dispersions. Biometrics 62:245-253

Anderson NH, Cummins KW (1979) Influences of diet on the life histories of aquatic insects. J Fish Board Can 36:335-342

Anderson MJ, Ellingsen KE, McArdle BH (2006) Multivariate dispersion as a measure of beta diversity. Ecol Lett 9:683-693

Anderson MJ, Gorley RN, Clarke KR (2008) PERMANOVA+ for PRIMER Guide to software and statistical methods. PRIMER-E, Plymouth

Beche LA, Mcelravy EP, Resh VH (2006) Long-term seasonal variation in the biological traits of benthic-macroinvertebrates in two Mediterranean-climate streams in California, USA. Freshw Biol 51:56-75

Bjelke U, Bohman IM, Herrmann J (2005) Temporal niches of shredders in lake littorals with possible implications on ecosystem functioning. Aquat Ecol 39:41-53

Bjurström L, Ruokonen T, Pursiainen M, Jones RI, Hämäläinen $H$ (2010) Impacts of the invasive signal crayfish on littoral macroinvertebrates of large boreal lakes: a pilot study in Lake Päijänne, Finland. Freshw Crayfish 17:177-182

Bubb DH, Lucas MC, Thom TJ, Rycroft P (2002) The potential use of PIT telemetry for identifying and tracking crayfish in their natural environment. Hydrobiologia 483:225-230

Bubb DH, Thom TJ, Lucas MC (2004) Movement and dispersal of the invasive signal crayfish Pacifastacus leniusculus in upland rivers. Freshw Biol 49:357-368

Bubb DH, Thom TJ, Lucas MC (2006) Movement, dispersal and refuge use of co-occurring introduced and native crayfish. Freshw Biol 5:1359-1368

Bunn SE, Arthington AH (2002) Basic principles and ecological consequences of altered flow regimes for aquatic biodiversity. Environ Manag 30:492-507

Clark JM, Kershner MW, Montemarano JJ (2013) Habitatspecific effects of particle size, current velocity, water 
depth, and predation risk on size-dependent crayfish distribution. Hydrobiologia 716:103-114

Clarke K, Gorley R (2006) PRIMER v6: user manual/tutorial. Primer-E, Ltd, Plymouth

Crandall KA, Buhay JE (2008) Global diversity of crayfish (Astacidae, Camaridae, and Parastacidae-Decapoda) in freshwater. Hydrobiologia 595:295-301

Crawford L, Yeomans WE, Adams CE (2006) The impact of introduced signal crayfish Pacifastacus leniusculus on stream invertebrate communities. Aquat Conserv 16:611-621

Crooks JA (2002) Characterizing ecosystem-level consequences of biological invasions: the role of ecosystem engineers. Oikos 97:153-166

Dorn NJ (2013) Consumptive effects of crayfish limit snail populations. Freshw Sci 32:1298-1308

Early R, Bradley BA, Dukes JS, Lawler JJ, Olden JD, Blumenthal DM, Gonzalez P, Grosholz ED, Ibañez I, Miller LP, Sorte CJ (2016) Global threats from invasive alien species in the twenty-first century and national response capacities. Nat Commun 7

Elliott JM (2008) The ecology of riffle beetles (Coleoptera: Elmidae). Freshw Rev 1:189-203

Elliott JM, Humpesch UH, Macan TT (1988) Larvae of the British Ephemeroptera. Freshwater Biological Association Scientific Publication No. 49, Cumbria, UK

Ercoli F, Ruokonen TJ, Koistinen S, Jones RI, Hämäläinen H (2015a) The introduced signal crayfish and native noble crayfish have different effects on sublittoral macroinvertebrate assemblages in boreal lakes. Freshw Biol 60:1688-1698

Ercoli F, Ruokonen TJ, Koistinen S, Jones RI, Hämäläinen H (2015b) Comparing the effects of introduced signal crayfish and native noble crayfish on the littoral invertebrate assemblages of boreal lakes. Freshw Sci 34:555-563

Faller M, Harvey G, Henshaw AJ, Bertoldi W, Bruno MC, England J (2016) River bank burrowing by invasive crayfish: spatial distribution, biophysical controls and biogeomorphic significance. Sci Total Environ 569:1190-1200

Fitter R, Manuel R (1986) Collins field guide to freshwater life. Collins, London

Fitzgerald DB, Tobler M, Winemiller KO (2016) From richer to poorer: successful invasion by freshwater fishes depends on species richness of donor and recipient basins. Glob Change Biol 22:2240-2450

Grant PR, Mackay RJ (1969) Ecological segregation of systematically related stream insects. Can J Zool 47:691-694

Growns I, Murphy JF, Jones JI (2016) The effects of altered flow and bed sediment on macroinvertebrates in stream mesocosms. Mar Freshw Res. doi:10.1071/MF15160

Guan R-Z, Wiles PR (1998) Feeding ecology of the signal crayfish Pacifastacus leniusculus in a British lowland river. Aquaculture 169:177-193

Haddaway NR, Vielle D, Mortimer RJG, Christmas M, Dunn AM (2014) Aquatic macroinvertbrate responses to native and non-native predators. Knowl Manag Aquat Ecosyst 415

Harvey GL, Moorhouse TP, Clifford NJ, Henshaw AJ, Johnson MF, Macdonald DW, Reid I, Rice S (2011) Evaluating the role of invasive aquatic species as drivers of fine sedimentrelated river management problems: the case of the signal crayfish (Pacifastacus leniusculus). Prog Phys Geogr 38:3-18

Holdich DM, Gydemo R, Rogers WD (1999) A review of possible methods for controlling nuisance populations of alien crayfish. In: Gheradi F, Holdich DM (eds) Crayfish in Europe as alien species: how to make the best of a bad situation. A.A. Balkema, Rotterdam

Holomuzki JR, Biggs BJ (2000) Taxon-specific responses to high-flow disturbance in streams: implications for population persistence. J N Am Benthol Soc 19:670-679

Hoverman JT, Auld JR, Relyea RA (2005) Putting prey back together again: integrating predator-induced behavior, morphology, and life history. Oecologia 144:481-491

Hudina S, Žganec K, Hock K (2015) Differences in aggressive behaviour along the expanding range of an invasive crayfish: an important component of invasion dynamics. Biol Invasions 17:3101-3112

Huryn AD, Wallace JB (2000) Life history and production of stream insects. Annu Rev Entomol 45:83-110

Hynes HBN (1972) The ecology of running waters. University of Toronto Press, Toronto

Johnson RC, Carreiro MM, Jin HS, Jack JD (2012) Within-year temporal variation and life-cycle seasonality affect stream macroinvertebrate community structure and biotic metrics. Ecol Ind 13:206-214

Johnson MF, Rice SP, Reid I (2014) The activity of signal crayfish (Pacifastacus leniusculus) in relation to thermal and hydraulic dynamics of an alluvial stream, UK. Hydrobiolgia 724:41-54

Jones JI, Murphy JF, Collins AL, Sear DA, Naden PS, Armitage PD (2012) The impact of fine sediment on macro-invertebrates. River Res Appl 28:1055-1071

Keller TR, Ruman LC (1998) Short-term crayfish effects on stream algae and invertebrates. J Freshw Ecol 13:97-104

Klose K, Cooper SD (2012) Contrasting effects of an invasive crayfish (Procambarus clarkii) on two temperate stream communities. Freshw Biol 57:526-540

Kouba A, Buřič M, Petrusek A (2015) Crayfish Species in Europe. In: Kozák P, Ďuriš Z, Petrusek A, Buřič M, Horká I, Kozubikova-Balcarová E, Policar, T (eds) Crayfish biology and culture. University of South Bohemia, Zátiŝi, Czech Republic

Lagrue C, Podgorniak T, Lecerf A, Bollache L (2014) An invasive species may be better than none: invasive signal and native noble crayfish have similar community effects. Freshw Biol 59:1982-1995

Larson S, Vaughan IP, Ormerod SJ (2010) Scale-dependant effects of fine sediment on temperature headwater invertebrates. Freshw Biol 54:203-219

Lewis SD (2002) Pacifastacus. In: Holdich DM (ed) Biology of freshwater crayfish. Blackwell Science Ltd, Oxford

Lodge DM, Hill AM (1994) Factors governing species composition, population size and productivity of coolwater crayfishes. Nord J Freshw Res 69:111-136

Mathers KL, Wood PJ (2016) Fine sediment deposition and interstitial flow effects on macroinvertebrate community composition within riffle heads and tails. Hydrobiologia 776:147-160

Mathers KL, Chadd RP, Dunbar MJ, Extence CA, Reeds J, Rice SP, Wood PJ (2016) The long-term effects of invasive signal crayfish (Pacifastacus leniusculus) on instream 
macroinvertebrate communities. Sci Total Environ 556:207-218

McCarthy JM, Hein CL, Olden JD, Zanden MJV (2006) Coupling long-term studies with meta-analysis to investigate impacts of non-native crayfish on zoobenthic communities. Freshw Biol 51:224-235

Momot WT, Gowing H, Jones PD (1978) The dynamics of crayfish and their role in ecosystems. Am Midl Nat 99:10-35

Moorhouse TP, Macdonald DW (2011) The effect of removal by trapping on body condition in populations of signal crayfish. Biol Conserv 144:1826-1831

Murphy JF, Giller PS (2000) Seasonal dynamics of macroinvertebrate assemblages in the benthos and associated with detritus packs in two low-order streams with different riparian vegetation. Freshw Biol 43:617-631

Nyström P (1999) Ecological impact of introduced and native crayfish on freshwater communities. In: Gheradi F, Holdich DM (eds) Crayfish in Europe as alien species. AA Balkema, Rotterdam

Nyström P, Svensson O, Lardner B, Brönmark C, Granelí W (2001) The influence of multiple introduced predators on a littoral pond community. Ecology 82:1023-1039

Peckarsky BL (1996) Alternative predator avoidance syndromes of stream-dwelling mayfly larvae. Ecology 77:1888-1905

R Development Core Team (2014) R: a language and environment for statistical computing. R Foundation for Statistical Computing, Vienna, Austria. ISBN 3-900051-07-0

Rice SP, Johnson MF, Mathers K, Reeds J, Extence C (2016) The importance of biotic entrainment for base flow fluvial sediment transport. J Geophys Res Earth Surf 121:890-906

Richards C, Bacon KL (1994) Influence of fine sediment on macroinvertebrate colonization of surface and hyporheic stream substrates. Great Basin Nat 106-113

Ruokonen TJ, Karjalainnen J, Hamalainen H (2014) Effects of an invasive crayfish on the littoral macroinvertebrates of large boreal lakes are habitat specific. Freshw Biol 59:12-25

Ruokonen TJ, Ercoli F, Hämäläinen H (2016) Are the effects of an invasive crayfish on lake littoral macroinvertebrate communities consistent over time? Knowl Manag Aquat Ecosyst 417
Simberloff D, Martin JL, Genovesi P, Maris V, Wardle DA, Aronson J, Courchamp F, Galil B, García-Berthou E, Pascal M, Pyšek P (2013) Impacts of biological invasions: what's what and the way forward. Trends Ecol Evol 28:58-66

Stenroth P, Nystrom P (2003) Exotic crayfish in a brown water stream: effects on juvenile trout, invertebrates and algae. Freshw Biol 48:466-475

Suren AM (2005) Effects of deposited sediment on patch selection by two grazing stream invertebrates. Hydrobiologia 549:205-218

Tonkin JD, Bogan MT, Bonada N, Rios-Touma B, Lytle DA (2017) Seasonality and predictability shape temporal species diversity. Ecology. doi:10.1002/ecy.1761

Turner AM, Fetterolf SA, Bernot RJ (1999) Predator identity and consumer behavior: differential effects of fish and crayfish on the habitat use of a freshwater snail. Oecologia 118:242-247

Usio N, Townsend CR (2004) Roles of crayfish: consequences of predation and bioturbation for stream invertebrates. Ecology 85:807-822

Vilà M, Espinar JL, Hejda M, Hulme PE, Jarošík V, Maron JL, Pergl J, Schaffner U, Sun Y, Pyšek P (2011) Ecological impacts of invasive alien plants: a meta-analysis of their effects on species, communities and ecosystems. Ecol Lett 14:702-708

Weber LM, Lodge DM (1990) Periphytic food and predatory crayfish: relative roles in determining snail distribution. Oecologia 82:33-39

Wilson KA, Magnuson JJ, Lodge DM, Hill AM, Kratz TK, Perry WL, Willis TV (2004) A long-term rusty crayfish (Orconectes rusticus) invasion: dispersal patterns and community change in a north temperate lake. Can J Fish Aquat Sci 61:2255-2266

Wood PJ, Armitage PD (1997) Biological effects of fine sediment in the lotic environment. Environ Manag 21:203-217

Wood PJ, Armitage PD (1999) Sediment deposition in a small lowland stream-management implications. Regul River 15:199-210

Wood PJ, Toone J, Greenwood MT, Armitage PD (2005) The response of four lotic macroinvertebrate taxa to burial by sediments. Arch Hydrobiol 163:145-162 